\title{
FAKTOR - FAKTOR YANG BERHUBUNGAN DENGAN WAKTU TANGGAP (RESPONSE TIME) PASIEN DI INSTALASI GAWAT DARURAT RUMAH SAKIT GRANDMED
}

\section{Tati Murni Karokaro', Kardina Hayati², Sari Desi Esta Ulina Sitepu ${ }^{3}$, Abdy Lestari Sitepu ${ }^{4}$}

\author{
1,2,3,4 Institut Kesehatan Medistra Lubuk Pakam \\ Fakultas Keperawatan dan Fisioterapi Program Studi Keperawatan S1 \\ Jl. Sudirman No 38 Lubuk Pakam, Kab. Deli Serdang SUMUT \\ e-mail: tatikarokaro612sp@gmail.com
}

DOI : https://doi.org/10.35451/jkf.v2i2.356

\begin{abstract}
Abstrak
Emergency installation (IGD) is the first place for patients to handle based on obesity. Response time can be calculated by minute, but the response time can be influenced by several factors: 1) The amount of energy available in $I G D, 2)$ facilities and infrastructures, 3) education. It is said to be timely when the response time required to respond does not exceed the average time specified. The Goals of this research was to know the factors related to the response time of the patient at the IGD HOSPITAL GrandmedLubukPakam in 2019. The research was conducted at IGD with a sample number of 30 respondents, used the Chi-Square test. The design was used analytical observation with a cross sectional approach. The Data collection techniques with total sampling using questionnaire and observation sheets. The Result of research based on respondent characteristics based on age of majority age 20 - 25 years, 66.7\%, female majority gender was 73.3\%, undergraduate education of nursing $83.3 \%$, and Chi-Square test can be concluded there was a nurse workload correlation with patient response time at IGD with significant value of 0.002 and nurse working period with patient response time in IGD with significant value 0.006 . From the research, it can be concluded that there was a time and workload correlation to the patient's response time at IGD. Suggestions for next researchers add to the research subject, the sampling techniques used, using case-study methods.
\end{abstract}

Keywords: Response time, IGD patient, Nurse

\section{Pendahuluan}

Rumah Sakit merupakan suatu instansi atau organisasi sosial dan kesehatan yang fungsi sebagai pelayanan yang memiliki manajemen yang baik dalam memberikan pelayanan kepada pasien seperti pelayanan yang secara menyeluruh, pengobatan sebagai bentuk 
peningkatan kualitas pelayanan asuhan, dimana bagian utama terdepan rumah sakit adalah Instalasi Gawat Darurat (IGD) yang merupakan tempat pertama pasien di tangani berdasarkan kegawatdaruratan ataupun pengelompokan triage pasien. (Musliha, 2015)

Pengelompokan triage yang dilakukan pada pasien adalah untuk menentukan kegawatdaruratan keadaan pasien sehingga dapat mencegah terjadinya kecacatan bahkan kematian. Oleh sebab itu, petugas IGD (dokter dan perawat) harus memiliki sertifikat dan memiliki kecepatan, ketrampilan dan kesiagaan yang lebih dari petugas medis di ruangan lain. Pelayanan yang di lakukan di IGD dapat di ukur dengan tahapan yaitu 1) tahap primer yaitu tanpa memberikan dukungan alat bantu diagnostik dan 2) tahap sekunder yaitu dengan memnerikan dukungan alat bantu diagnistik. Setiap melakukan tindakan pada pasien yang masuk ke IGD, maka perawat dan tim medis lainnya wajib mengkaji pasien dengan tahapan: 1) Airway, 2) Breathing, 3) Circulation, 4) Drug Defibrilator Disability, (Leading Practice in Emergency Departement, 2010, Musliha, 2015, Soetrisno,2013 dan Basoeki dkk, 2012).

\section{Gambar 1. Ruang IGD}

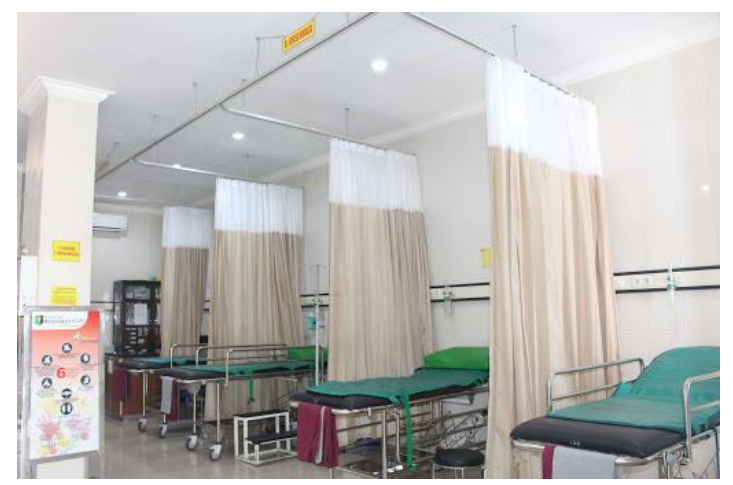

Pelayanan yang di lakukan di IGD dapat di ukur dengan tahapan yaitu 1) tahap primer yaitu tanpa memberikan dukungan alat bantu diagnostik dan 2) tahap sekunder yaitu dengan memberikan dukungan alat bantu diagnistik. Setiap melakukan tindakan pada pasien yang masuk ke IGD, maka perawat dan tim medis lainnya wajib mengkaji pasien dengan tahapan: 1) Airway, 2) Breathing, 3) Circulation, 4) Drug Defibrilator Disability. (Ines, 2016 dan Rima, 2015).

Waktu tanggap dapat dihitung dengan hitungan menit, namun waktu tanggap dapat dipengaruhi beberapa factor yaitu: 1) jumlah tenaga yang tersedia di IGD, 2) sarana dan prasarana, 3) pendidikan, dan faktor lain yang mendukung. Dikatakan tepat waktu apabila waktu tanggap yang diperlukan dalam memberikan respon tidak melebihi waktu rata-rata atau standar yang sudah di tentukan. Pelaksanaan waktu tanggap yang memadai di Indonesia masih memerlukan evaluasi lebih lanjut dan yang menjadi indikator keberhasilan waktu tanggap penderita gawat darurat adalah kecepatan dalam memberikan pertolongan kepada pasien baik, keadaan rutin sehari-hari maupun sewaktu bencana serta bantuan yang diberikan untuk menyelamatkan nyawa atau mencegah cacat. (Rima, 2015, Soetrisno,2013 dan Yuliati, 2018).

Waktu tanggap yang diberikan oleh petugas kesehatan di IGD sangat membantu pasien maupun keluarga karena dapat membantu mengurangi biaya pengobatan, namun Kecepatan dan ketepatan pelayanan kesehatan yang diberikan tenaga kesehatan kepada pasien haruslah sesuai dengan standar yang sudah ditentukan sesuai dengan kompetensi dan kemampuan tenaga medis agar dapat menjamin dalam memberikan pelayanan kegawatdaruratan yang cepat dan tepat. Hal ini dapat dicapai dengan meningkatkan sarana, prasarana, sumber daya manusia dan manajemen rumahsakit/puskesmas sesuai standar. (Wilde, 2009 dan Soetrisno,2013).

Keberhasilan tindakan dalam mengatasi kegawatdaruratan dapat dinilai dari: 1) Pelayanan pertama pada saat terjadi kegawatdaruratan dan dapat dikategorikan terlambat apabila tindakan yang di berikan kepada pasien $>5$ menit, 2) Petugas IGD adalah petugas yang bekerja di IGD Rumah sakit yang telah di latih Penanggulangan Penderita Gawat Darurat (PPGD), 3) Tindakan untuk 
menyelamatkan hidupp pasien jiwa yang sedang gawat darurat. (Patricia, 2013).

Faktor - faktor yang dapat mempengaruhi waktu tanggap perawat di IGD meliputi: 1) karakter pasien, 2) penempatan staf, 3) Brangkar, Rostul dan alat lainnya yang digunakan untuk memindahkan pasien ke ambulans atau tempat tidur) 4) petugas kesehatan, waktu ketibaan pasien, 5) pelaksanaan manajemen, 6) strategi pemeriksaan, 7) penanganan yang dipilih, 8) masa kerja, 9) Pendidikan, 10) Beban kerja (Jordiawan, 2015, Kemenkes, 2009 dan Munandar, 2012).

\section{Gambar 2. Waktu Tanggap Petugas IGD}

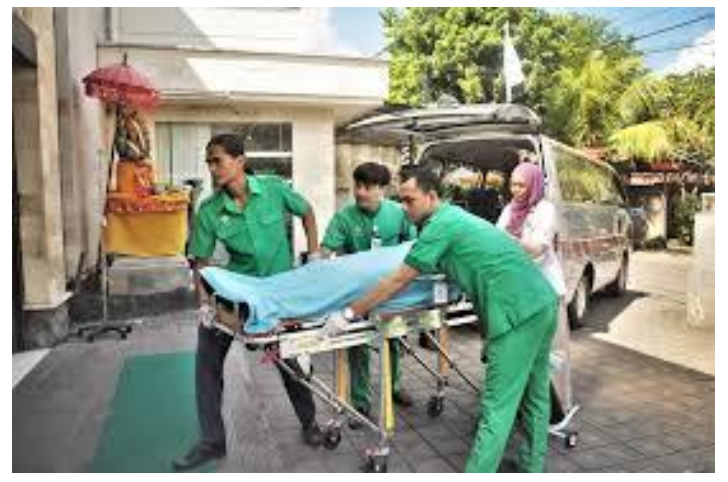

Data kunjungan (IGD) Rumah Sakit yang ada di Indonesia adalah 5.602.306 pasien $(15,1 \%)$ dari total kunjungan. Penanganan pasien di IGD BLU RSUP Prof. Dr. R. D. Kandou memiliki waktu tanggap >5 menit sebanyak $17(56,7 \%)$. Petugas IGD Rumah Sakit Umum Daerah Labuang Baji memiliki waktu tanggap 28 kali $(90,3 \%)$. Di IGD RSD Balung, waktu tanggap penanganan 0 menit sebanyak $60,0 \%$, dan sebagian besar responden yang menyatakan sangat sesuai dengan waktu tanggap dalam pelayanan dengan rentang waktu 2 hingga 30 menit dalam pelayanan kegawatdaruratan sebanyak 12 responden $(40,0 \%)$ dari 30 responden. (Kemenkes RI, 2018, Surtiningsih, 2016, Maatilu tahun 2014 dan Risamdani, 2015).

Waktu tanggapdi IGD rumah sakit memiliki kecepatan dan ketepatan yang baik, contoh: pasien datang ke IGD pada pukil 20.00 wib dengan keluhan sesak napas, perawat langsung melekukan pengkajian dasar dimana perawat melakukan penghitungan frekwensi pernapasan pasien dan didapat hasilnya $28 \mathrm{x} /$ menit. Dari hasil pengkajian maka perawat langsung memasang nasal canul dengan oksigen 2 liter/menit, pada pukul 20.03 dan memberikan posisi semi fowler. Kemudian perawat melaporkan keadaan pasien dan tindakan yang sudah diberikan kepada pasien kepada dokter jaga pukul 20.07. Setelah itu dokter langsung memeriksa keadaan pasien pukul 20.10 dan langsung memberikan terapi pukul 20.13. Waktu tanggap dipengaruhi oleh faktor internal dan eksternal yang mempengaruhi memberikan pelayanan kesehatanantara lain karakteristik pasien (triage), keterampilan dan beban kerja perawat yaitu 67,5\%, fasilitas dan sarana pendukung $80,0 \%$, standar prosedur pelayanan $77,5 \%$. (Girsang, 2005, Yoon, 2013, Siahaan, 2013 dan Musliha, 2015)

\section{Gambar 3. Fasilitas Ruang IGD}

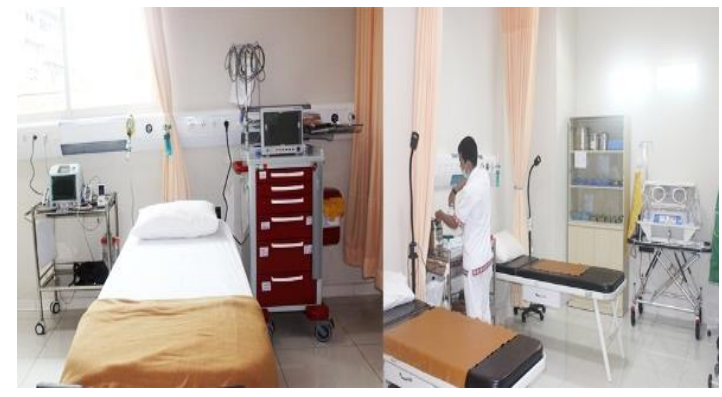

Berdasarkan studi pendahuluan yang dilakukan penulis pada tanggal 25 Oktober 2019, didapatkan data jumlah pasien yang masuk IGD RS Grandmed selama bulan Januari -September 2019 adalah 80.229 pasien. Rata-rata jumlah pasien setiap hari yang masuk mencapai 92 pasien. Ada beberapa keluarga maupun pasien mengeluh dengan pelayanan di Instalasi Gawat Darurat RS Grandmed dengan triage bewarna hijau bahwa kurang perhatian seperti pasien yang masuk ke IGD dengan triage bewarna kuning dan merah, namun ada beberapa pasien yang tidak sesuai dengan penempatan triage yang sudah di tentukan. Jumlah tenaga perawat yang dinas di IGD RS Grandmed berjumlah 30 perawat, pembagian team diatur oleh kepala ruang IGD. Sebagian perawat yang bertugas di IGD juga bertugas di 
Unit Endoscopy, sehingga beban kerja perawat IGD menjadi 2 bagian, masih ada perawata di IGD yang belum memiliki sertifikat perawat IGD dan masa kerja yang kurang dari 3 Bulan. Dari keterangan kepala ruang IGD belum ada evaluasi tentang waktu tanggap dan faktor-faktor yang mempengaruhinya (Rekam Medis RS Grandmed, 2019).

\section{METODE PENELITIAN}

Penelitian ini dilaksanakan di IGD Rumah Sakit Grandme, sampel yang diambil adalah seluruh perawat IGD yaitu 30 orang dengan kriteria: 1) perawat yang bekerja gi IGD, 2) tingkat pendidikan minimal D3, 3) masa kerja minimal 3 bulan atau telah selesai melaksanakan masa training. Instrumen yang digunakan adalah Kuesioner yang di adopsi dari penelitian sebelumnya dari Surtiningsih, 2016, Rima, Wahyu, 2015, dan Ines, Marianne, 2016 berhubungan dengan beban dan masa kerja serta waktu tanggap, sehingga peneliti tidak melakukan ujia validitas maupun reabilitas. Menggunakan Uji Chi-Square. desain yang digunakan adalah observasi analitik dengan pendekatan cross sectional. Teknik pengumpulan data yaitu melakukan wawancara langsung kepada responden berpedoman pada kuesioner mengenai masa kerja, beban kerja, sarana dan prasarana dan waktu tanggap. Alur penelitian ini dapat dilihat pada figure 4 alur pelaksanaan penelitian di bawah ini .

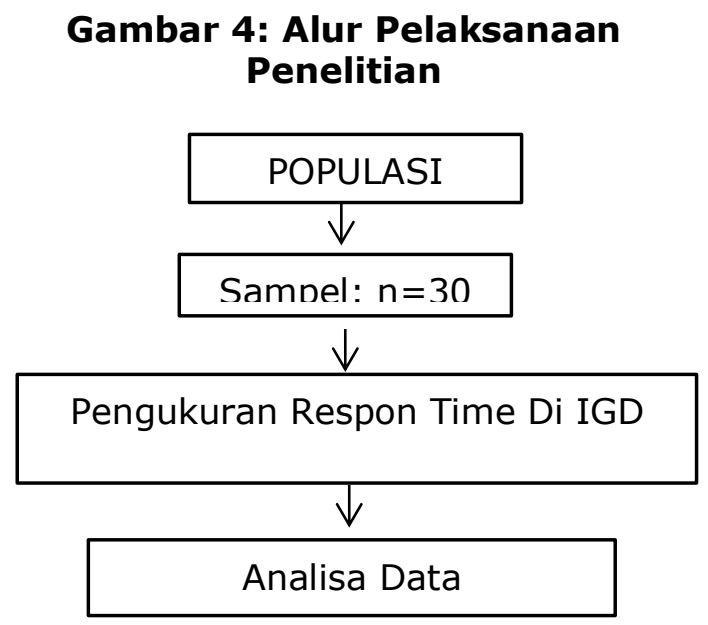

3. HASIL
Berdasarkan Tabel 1 Karakteristik Responden berdasarkan umur mayoritas usia 20 - 25 tahun yaitu $66,7 \%$, jenis kelamin mayoritas perempuan yaitu $73,3 \%$, pendidikan Sarjana Keperawatan $83,3 \%$.

Tabel 4.1. Karakteristik Responden Yang Berhubungan Dengan Waktu Tanggap (Respon Time) Pasien di IGD

\begin{tabular}{ccc}
\hline $\begin{array}{c}\text { Karakteristik } \\
\text { Responden }\end{array}$ & Frekwensi & (\%) \\
\hline Umur & & \\
$20-25$ tahun & 20 & 66,7 \\
$26-30$ tahun & 9 & 30,0 \\
$31-35$ tahun & 1 & 3,3 \\
Jenis kelamin & & \\
Laki - laki & 8 & 26,7 \\
Perempuan & 22 & 73,3 \\
Pendidikan & & \\
D3 keperawatan & 5 & 16,7 \\
Sarjana keperawatan & 25 & 83,3 \\
\hline
\end{tabular}

Berdasarkan Tabel 2 faktor - faktor yang berhubungan dengan Waktu Tanggap berdasarkan masa kerja mayoritas $\leq 2$ tahun $56,7 \%$, beban kerja mayoritas rendah 56,7\%, sarana dan prasarana mayoritas lengkap $70 \%$, waktu tanggap mayoritas $\geq 5$ menit $60,0 \%$.

Tabel 4.2. Faktor - Faktor Yang Berhubungan Dengan Waktu Tanggap (Respon Time) Pasien

\begin{tabular}{|c|c|c|}
\hline Variabel & Frekuensi & $(\%)$ \\
\hline \multicolumn{3}{|l|}{ Masa Kerja } \\
\hline$\leq 2$ tahun & 17 & 56,7 \\
\hline$\geq 2$ tahun & 13 & 43,3 \\
\hline \multicolumn{3}{|l|}{ Beban Kerja } \\
\hline Rendah & 17 & 56,7 \\
\hline Tinggi & 13 & 43,3 \\
\hline \multicolumn{3}{|l|}{ Sarana \& } \\
\hline Prasarana & & \\
\hline Tidak lengkap & 9 & 30,0 \\
\hline Lengkap & 21 & 70,0 \\
\hline \multicolumn{3}{|l|}{$\begin{array}{l}\text { Waktu Tanggap } \\
\text { (Respon Time) }\end{array}$} \\
\hline$\leq 5$ menit & 12 & 40,0 \\
\hline$\geq 5$ menit & 18 & 60,0 \\
\hline
\end{tabular}

Berdasarkan Tabel 3 Hubungan Masa Kerja Dengan Waktu Tanggap (Respon Time) Pasien di IGD RS Grandmed bahwa dari $17(56,7 \%)$ perawat pelaksana yang masa kerja $\leq 2$ tahun ada $3(10,0 \%)$ perawat pelaksana menangani pasien 
IGD dengan waktu tanggap (respon time) $\leq 5$ menit kepada pasien dan $14(46,7 \%)$ perawat pelaksana menangani pasien IGD dengan waktu tanggap (respon time) $\geq 5$ menit. Hal ini menunjukkan angka yang lebih tinggi dibandingkan dengan 13 $(43,3 \%)$ perawat pelaksana yang masa kerja $\geq 2$ tahun ada $9(30,0 \%)$ perawat pelaksana menangani pasien IGD dengan waktu tanggap (respon time) $\leq 5$ menit kepada pasien dan $4(13,3 \%)$ perawat pelaksana lainnya menangani pasien IGD dengan waktu tanggap (respon time) $\geq 5$ menit.

Tabel 4.3. Hubungan Masa Kerja Dengan Waktu Tanggap (Respon Time) Pasien di IGD

\begin{tabular}{|c|c|c|c|c|c|c|c|}
\hline \multirow{3}{*}{$\begin{array}{l}\text { Masa } \\
\text { Kerja }\end{array}$} & \multicolumn{4}{|c|}{$\begin{array}{c}\text { Waktu Tanggap } \\
\text { (Respon Time) }\end{array}$} & \multirow{2}{*}{\multicolumn{2}{|c|}{ Jumlah }} & \multirow{3}{*}{$P$} \\
\hline & \multicolumn{2}{|c|}{$\begin{array}{c}\leq 5 \\
\text { menit }\end{array}$} & \multicolumn{2}{|c|}{$\geq 5$ menit } & & & \\
\hline & $\mathrm{n}$ & $\%$ & $\mathbf{N}$ & $\%$ & $n$ & $\%$ & \\
\hline$\leq 2$ thn & 3 & 10 & 14 & 46,7 & 17 & 56,7 & \\
\hline$\geq 2$ thn & 9 & 30 & 4 & 13,3 & 13 & 43,3 & 0,00 \\
\hline Jumlah & 12 & 40 & 18 & 60,0 & 30 & 100 & \\
\hline
\end{tabular}

Berdasarkan Tabel 4 Hubungan Beban Kerja Dengan Waktu Tanggap (Respon Time) Pasien dapat dilihat bahwa dari 17 $(56,7 \%)$ perawat pelaksana yang beban kerja rendah ada $11(36,7 \%)$ perawat pelaksana mengaku menangani pasien IGD dengan waktu tanggap (respon time) $\leq 5$ menit kepada pasien dan $6(20,0 \%)$ perawat pelaksana mengaku menagani pasien IGD dengan waktu tanggap (respon time) $\geq 5$ menit. $\mathrm{Hal}$ ini menunjukkan angka yang lebih tinggi dibandingkan dengan $13 \quad(43,3 \%)$ perawat pelaksana yang beban kerja tinggi ada $1(3,3 \%)$ perawat pelaksana mengaku menangani pasien IGD dengan waktu tanggap (respon time) $\leq 5$ menit kepada pasien dan $12(40,0 \%)$ perawat pelaksana lainnya mengaku menangani pasien IGD dengan waktu tanggap (respon time) $\geq 5$ menit.

Tabel 4.4. Hubungan Beban Kerja Dengan Waktu Tanggap (Respon Time) Pasien di IGD

\begin{tabular}{|c|c|c|c|c|c|c|c|}
\hline \multirow{3}{*}{$\begin{array}{c}\text { Beban } \\
\text { Kerja }\end{array}$} & \multicolumn{4}{|c|}{$\begin{array}{c}\text { Waktu Tanggap } \\
\text { (Respon Time) }\end{array}$} & \multirow{2}{*}{\multicolumn{2}{|c|}{ Jumlah }} & \multirow{3}{*}{$\boldsymbol{P}$} \\
\hline & \multicolumn{2}{|c|}{$\leq 5$ menit } & \multicolumn{2}{|c|}{$\geq 5$ menit } & & & \\
\hline & $\mathbf{n}$ & $\%$ & $\mathbf{n}$ & $\%$ & $\mathbf{n}$ & $\%$ & \\
\hline Rendah & 11 & 36,7 & 6 & 20,0 & 17 & 56,7 & \\
\hline Tinggi & 1 & 3,3 & 12 & 40,0 & 13 & 43,3 & 0,002 \\
\hline Jumlah & 12 & 40,0 & 18 & 60,0 & 30 & 100 & \\
\hline
\end{tabular}

Berdasarkan Tabel 5 Hubungan Sarana Dan Prasarana Dengan Waktu Tanggap bahwa dari $9(30,0 \%)$ perawat pelaksana yang sarana dan prasarana tidak lengkap ada $2(6,7 \%)$ perawat pelaksana mengaku menangani pasien IGD dengan waktu tanggap (respon time) $\leq 5$ menit kepada pasien dan $7(23,3 \%)$ perawat pelaksana mengaku menagani pasien IGD dengan waktu tanggap (respon time) $\geq 5$ menit. Hal ini menunjukkan angka yang lebih rendah dibandingkan dengan $21(70,0 \%)$ perawat pelaksana yang beban kerja tinggi ada $10 \quad(33,3 \%)$ perawat pelaksana mengaku menangani pasien IGD dengan waktu tanggap (respon time) $\leq 5$ menit kepada pasien dan $11(35,7 \%)$ perawat pelaksana lainnya mengaku menangani pasien IGD dengan waktu tanggap (respon time) $\geq 5$ menit.

Tabel 4.5. Hubungan Sarana Dan Prasarana Dengan Waktu Tanggap (Respon Time) Pasien di IGD

\begin{tabular}{|c|c|c|c|c|c|c|c|}
\hline \multirow{3}{*}{$\begin{array}{c}\text { Sarana } \\
\text { dan } \\
\text { Prasarana }\end{array}$} & \multicolumn{4}{|c|}{$\begin{array}{c}\text { Waktu Tanggap } \\
\text { (Respon Time) }\end{array}$} & \multirow{2}{*}{\multicolumn{2}{|c|}{ Jumlah }} & \multirow{3}{*}{$\boldsymbol{P}$} \\
\hline & \multicolumn{2}{|c|}{$\leq 5$ menit } & \multicolumn{2}{|c|}{$\geq 5$ menit } & & & \\
\hline & $\mathbf{n}$ & $\%$ & $\mathbf{n}$ & $\%$ & $\mathbf{n}$ & $\%$ & \\
\hline $\begin{array}{l}\text { Tidak } \\
\text { lengkap }\end{array}$ & 2 & 6,7 & 7 & 23,3 & 9 & 30 & \\
\hline Lengkap & 10 & 33,3 & 11 & 35,7 & 21 & 70 & 0,187 \\
\hline Jumlah & 12 & 40,0 & 18 & 60,0 & 30 & 100 & \\
\hline
\end{tabular}

\section{Pembahasan}

\section{Faktor Masa Kerja Perawat Yang Berhubungan Dengan Waktu Tanggap (Respon Time) Pasien di IGD}

Masa atau pengalaman kerja sangatlah penting dalam memberikan pelayanan yang prima untuk meningkatkan pengetahuan maupun keterampilan, sehingga dengan masa kerja ataupu pengalaman kerja yang panjang dapat meningkatkan keterampilan dan metode dalam bekerja sehingga dapat memiliki banyak pengalaman dengan masalah atau kasus - kasus kegawatdaruratan yang terjadi sangat berpengaruh terhadap respon time petugas/pekerja. Masa kerja atau lama kerja adalah proses pembentukan pengetahuan atau keterampilan tentang metode suatu pekerjaan karena keterlibatan individu/petugas tersebut 
dalam pelaksanaan tugas pekerjaan, sehingga dengan lama kerja yang panjang dapat meningkatkan teknik dan metode dalam bekerja sehingga dapat memiliki banyak pengalaman terkait dengan masalah atau kasus - kasus kegawatdaruratan yang terjadi sangat berpengaruh terhadap respon time petugas/pekerja. (Suyanto, 2010, Maatilu 2014 dan Haryatun, 2018)

Berdasarkan pengamatan selama meneliti di IGD masa kerja perawat yang bertugas sangat berhubungan dengan lamanya bekerja dan pengalaman yang dimiliki ketika bekerja di instalasi sebelumnya, perawat fresh gruaded masih butuh bimbingan dan pelatihan dasar kegawatdaruratan yang masuk/berobat ke Instalasi IGD RS Grandmed sesuai dengan pengelompokan triage dan respon time sesuai kebijakan RS Grandmed. Peneliti juga menyadari bahwa masa kerja juga sangat erat kaitannya dengan waktu tanggap (response time) pada pasien triage warna merah dikarenakan keterampilan dan kompetensi perawat yang memiliki pelatihan tentang BTCLS sehingga dapat menangani pasien dengan benar dan sesuai standar prosedur operasional, perlu adanya peningkatan dalam memberikan pelatihan kepada perawat yang fresh gruated untuk mengikuti pelatihan dasar kegawatdaruratan sehingga waktu tanggap (response time) pada pasien dapat ditangani sesuai kebijakan RS Grandmed dan juga Peraturan Kesehatan.

\section{Gambar 5: Pelatihan Dasar Kegawatdaruratan}

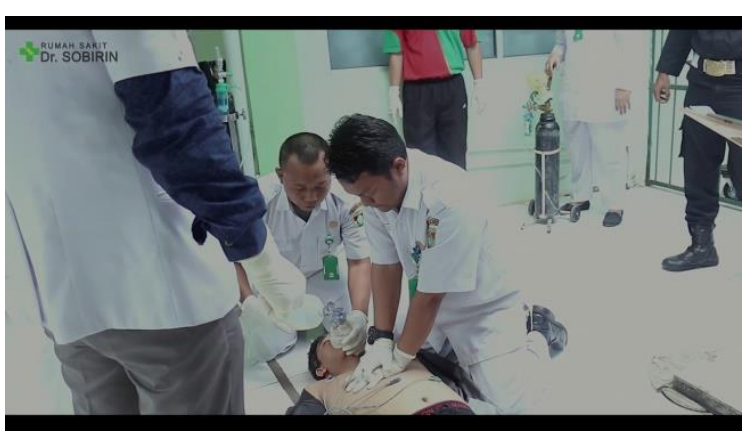

Faktor Beban Kerja Perawat Yang Berhubungan Dengan Waktu Tanggap (Respon Time) di IGD
Hasil penelitian menunjukkan ada hubungan antara beban kerja dengan waktu tanggap (respon time) di IGD RS Grandmed Lubuk Pakam $p$ value 0,002. Hal ini ditunjukkan perawat yang beban kerja rendah menangani pasien dengan waktu tanggap (respon time) $\geq 5$ menit.

Beban kerja merupakan suatu pekerjaan yang harus di kerjakan oleh seseorang seperti: 1) mengangkat, 2) mengangkut, 3) merawat, 4) mendorong. Beban kerja yang dikerjakan oleh perawat di IGD mengalami peningkatan beban kerja dan masih mengalami kekurangan perawat sehingga beberapa perawat IGD yang memiliki kompetensi bidang khusus endoscopy harus menjalani pekerjaan yang double. WHO mengemukakan bahwa beban kerja berlebih dapat mengakibatkan perawat mengalami penurunan: 1) tingkat kesehatan, 2) motivasi kerja, 3) kualitas pelayanan keperawatan dan kegagalan melakukan tindakan pertolongan terhadap pasien. Dalam penelitian ini didapatkan bahwa perawat dengan beban kerja rendah dapat melakukan penanganan pada pasien IGD dengan waktu tanggap (respon time) $\leq 5$ menit, akan tetapi ditemukan $40 \%$ terdapat pada perawat yang beban kerja tinggi melakukan penanganan pada pasien $\geq 5$ menit. Hal ini menunjukkan bahwa apabila beban kerja rendah maka perawat dan tim medis lainnya akan semakin cepat dalam memberikan waktu tanggap menangani pasien yang ada di IGD. (Surtiningsih. 2016, Sutrisno. 2013).

Berdasarkan pengamatan selama meneliti di IGD beban kerja yang tidak merata didapat oleh perawat, dimana perawat baru beban kerja selalu lebih banyak dibandingkan oleh perawat senior, lebih berat beban pada perawat laki laki dari pada perempuan. Hal ini seharusnya tidak terjadi karena pembagian beban kerja kepada perawat seharusnya berdasarkan jabatan apakah sebagai kepala ruangan, clinical instruktur, ketua tim atau perawat pelaksana, dapat juga di lihat dari pembagian beban kerja berdasarkan ketentuan atau kebijakan dari Rumah Sakit GrandMed serta Kebijakan dari Persatuan Rumah Sakit Indinesia (Persi). 


\section{Gambar 6: Waktu Tanggap Perawat Terhadap Pasien di IGD}

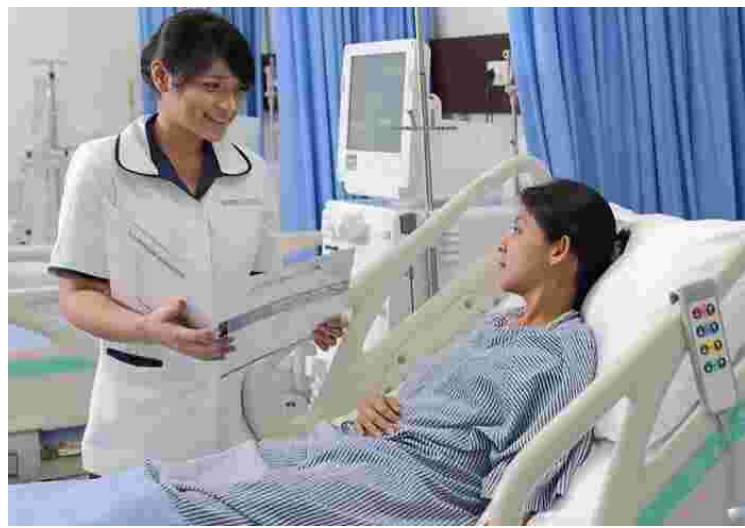

\section{Faktor Sarana dan Prasarana Yang Berhubungan Dengan Waktu Tanggap (Respon Time) di IGD}

Sarana merupakan alat yang digunakan untuk dalam mencapai maksud dan tujuan sedangkan Prasarana adalah alat yang digunakan sebagai penunjang utama untuk menjalankan proses seperti: 1) usaha, 2) pembangunan, 3) proyek). Sarana dan prasarana adalah fasilitas yang saling mendukung karena saling berkaitan antara satu dengan yang lainnya. Dalam memberikan pelayanan kegawatraruratan maka diperlukan Kecepatan dan ketepatan dalam memberikan pada pasien sesuai dengan standar yang ditentukan agar dapat menjamin penanganan kegawatdaruratan dan waktu tanggap cepat dan tepat. Berdasarkan penelitian yang saya lakukan di IGD RS Grandmed untuk tersedianya sarana dan prasarana sudah sangat lengkap dan tidak terkendala saat menangani pasien dengan gawat darurat. Akan tetapi diperlukan perawatan peralatan yang lebih akurat agar peralatan yang pada saat digunakan untuk penanganan pasien dengan kegawatdarutan triage hijau tidak terkendala. Hal ini ditunjukkan sarana dan prasarana yang dimiliki oleh RS Grandmed sudah lengkap dan dapat menanggani pasien kegawatdarutan dengan waktu tanggap (respon time) $\leq 5$ menit. Sejalan dengan penelitian yang di IGD RSUP Prof. DR. R. D. Kandou bahwa tidak ada hubungan antara sarana dan prasarana dengan waktu tanggap perawat. (Notoadmojo, 2003 dan Maatilu (2018).

\section{Gambar 7: Sarana dan Prasarana Ruang IGD}

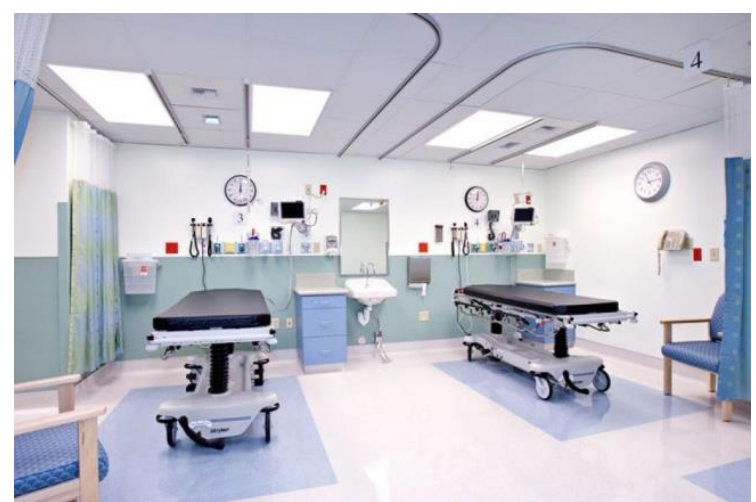

\section{KESIMPULAN}

Ada hubungan masa kerja perawat dengan waktu tanggap (response time) pasien di IGD RS Grandmed Lubuk Pakam dengan nilai signifikan 0,006.

Ada hubungan beban kerja perawat dengan waktu tanggap (response time) pasien di IGD RS Grandmed Lubuk Pakam dengan nilai signifikan 0,002, Tidak ada hubungan sarana dan prasarana dengan waktu tanggap (response time) pasien di IGD RS Grandmed Lubuk Pakam dengan nilai signifikan 0,187.

\section{SARAN}

\section{Bagi Perawat}

Dapat memberikan masukan kepada perawat untuk evaluasi faktor - faktor yang berhubungan kinerja perawat dengan waktu tanggap (response time) dalam menangani pasien gawat darurat.

\section{Bagi Rumah Sakit}

Agar meningkatkan kualitas dan mutu pelayanan yang cepat, dan mampu menyelamatkan pasien gawat darurat dengan memberikan perawat IGD 
pelatihan yang terus menerus tentang menangani pasien kegawatdaruratan.

\section{Bagi Pendidikan}

Menambah wawasan kepada mahasiswa fakultas keperawatan dan Fisioterapi tentang penanganan pasien gawatdarurat dengan waktu tanggap (response time)

\section{Bagi Peneliti Selanjutnya}

Menambah subjek penelitian, teknik pengambilan sampel yang digunakan, dengan menggunakan metode yang bersifat studi kasus (case control).

\section{DAFTAR PUSTAKA}

Basoeki, A.P. 2012. Penanggulangan penderita gawat darurat anestesiologi \& reanimasi. Surabaya: FK. Unair.

Girsang. 2015. Faktor faktor yang Berhubungan Dengan Waktu Tanggap Petugas Kesehatan.

Haryatun., 2008. Perbedaan Waktu Tanggap Tindakan Keperawatan Pasien Cedera Kepala Kategori 1 - V di Instalasi Gawat Darurat RSUD dr. Moewardi. Berita IImu Keperawatan, ISSN 1979-2697, Vol. 1. No.70 2, Juni 2008 69-74.

Ines, Marianne. 2016. Faktor faktor Yang Mempengaruhi Waktu Tanggap Pasien Di Instalasi Gawat Darurat Rumah Sakit " $X$ " Tahun 2016. Jurnal Bidang Ilmu Kesehatan Vol. 2 No. 8.

Jordiawan (2015). Analisis Faktor-faktor yang Mempengaruhi Response Time pada Pasien Rawat Jalan Pengguna Jaminan Kesehatan Nasional di Tempat Pendaftaran Rawat Jalan Rumah Sakit Umum Daerah Wangaya. Fakultas Kedokteran Universitas Udayana.

Karokaro, T., \& Hasrawi, L (2019). The Effect Of Endotracheal Tube (Ett) Suction Measures On Our Saturation Levels In Failed Patients In Icu Grandmed Hospital. Jurnal Keperawatan dan Fisioterapi (JKF), e-ISSN 2655-0830 Vol. 2 No.1 Edisi Mei-Oktober 2019 https://ejournal.medistra.ac.id/inde x.php.JFK
Kementerian Kesehatan Republik Indonesia. 2018. Profil Kesehatan Indonesia Tahun 2017.

Kementerian Kesehatan Republik Indonesia. 2012. Penanganan Pasien Gawat Darurat.

Leading Practices in emergency Departement Patient Experience. 2010. Ontario Hospital Asociation.

Maatilu. 2014. Faktor faktor Yang Berhubungan Dengan Response Time Perawat pada Penanganan Pasien Gawat Darurat di IGD BLU RSUP Prof.Dr.R.D Kandou Manado.

Munandar, A. S. 2012. Psikologi Industri dan Organisasi. Jakarta : UI-Press

Musliha. 2015. Keperawatan Gawat Darurat. Yogyakarta: Nuha Medika.

Nursalam. $2014 . \quad$ Manajemen keperawatan aplikasi dalam praktik keperawatan profesional edisi 4. Jakarta : Salemba Medika.

Patricia Gonce, 2013. Keperawatan Kritis:Pendekatan Asuhan Holistik. Edisi 8 volume 2. Jakarta: EGC.

Rima, Wahyu. 2015. Hubungan Faktor Faktor Eksternal Dengan Response Time Perawat Dalam Penanganan Pasien Gawat Darurat Di IGD RSUP Prof. DR.R.D. Kandou Manado. Ejournal Keperawatan Vol. 3.

Rumah Sakit GranMed. 2019. Data Rekam Medis RS Grandmed Tahun 2019.

Risamdani, R, 2015. Hubungan Penatalaksanaan Penaganan Gawat darurat Dengan waktu Tanggap (Respon Time) Keperawatan di Ruang Instalasi Gawat Darurat Rumah sakit Permata Bunda Tahun 2014. Tesis. Fakultas Ilmu Kesehatan Masyarakat. Universitas Sumatera Utara. Medan.

Siahaan., 2013. Setiap Unit Gawat Darurat Rumah Sakit Harus Memiliki 'Response Time' yang Cepat dan Tepat. http://kesehatan. kompasiana.com/medis/2013/02/11 /setiap-unit-gawat-darurat-rumahsakitharus-memiliki-response-timeyang-cepat-dan-tepat-527515.html.

Surtiningsih. 2016. Penerapan Response Time Perawat Dalam Pelaksanaan Penentuan Prioritas Penanganan Kegawatdaruratan Pada Pasien Kecelakaan di IGD RSD Balung. 
Received: 30 Maret 2020 :: Accepted: 21 April 2020 :: Published: 30 April 2020

Sutrisno. 2013. Keperawatan Kegawat Daruratan. Jakarta: Media Aesculapins.

Suyanto., 2010. Pengaruh Strategi Respon Time di Instalasi Gawat Darurat dalam Upaya Meningkatkan Kepuasan Pelanggan di Rumah Sakit Semen Gresik. Jurnal

Wilde, E. T. 2009. Do Emergency Medical System Response Times Matter for health Outcome. Columbia University: New York.

Yoon et al. (2013). Analysis Of Factor Influecing Length of Stay In the Emergency Depatment. http://www.cnbi.nml.

Yuliati. 2018. Buku Ajar Keperawatan Gerontik. T. Ari, Ed). Jakarta: Cv. Trans Info Medika. 